\title{
Documental interactivo transmedia en Latinoamérica. La Escuela Internacional de Cine y Televisión de San Antonio de los Baños (Cuba) a través del caso de Metáfora Viva
}

\author{
JosÉ-LUIS TORRES-MARTíN \\ Universidad de Málaga, España \\ jltorres@uma.es \\ https://orcid.org/0000-0001-6556-1560
}

\author{
Andrea Castro-Martínez \\ Universidad de Málaga, España \\ andreacastro@uma.es \\ https://orcid.org/0000-0002-2775-625X
}

\author{
Pablo Díaz-Morilla \\ Universidad de Málaga - EADE Málaga, España \\ pablodmorilla@uma.es \\ https://orcid.org/0000-0002-7914-3391
}

\section{Interactive transmedia documentary in Latin America. The Escuela Internacional de Cine y Televisión of San Antonio de los Baños (Cuba) through the case of Metáfora Viva}

\section{RESUMEN ABSTRACT}

Este estudio de caso sobre el documental interactivo Metáfora Viva, 30 años de orden y caos pretende analizar la transmedialidad y la interactividad del proyecto pro-

fundizando en su proceso creativo y de producción, sus estrategias narrativas y los rasgos que lo unen al al resto de producción documental interactiva realizada en Latinoamérica en la actualidad. Se emplea un enfoque cualitativo basado en el análisis de la pieza audiovisual, la entrevista en profundidad al profesor a cargo del proyecto, Tomás Crowder, y el análisis documental. Los resultados muestran que a través de distintos recursos hipertextuales y el montaje multicapa se logra un producto transmedia interactivo que ofrece un recorrido por los 30 años de historia de la Escuela

Internacional de Cine y Televisión de San Antonio de los Baños. Metáfora Viva, a través de distintos menús y contenidos complementarios, ofrece al espectador la oportunidad de configurar una experiencia propia de consumo audiovisual de no ficción.

PALABRAS CLAVE

Documental interactivo; Webdoc; Transmedia; Latinoamérica; Cuba; EICTV.
This case study on the interactive documentary Metáfora Viva, 30 años de orden y caos aims to analyse the transmediality and interactivity of the project by delving into its creative and production process, its narrative strategies and the features that unite it with the rest of the interactive documentary production currently being made in Latin America. A qualitative approach is used based on the analysis of the audiovisual piece, an in-depth interview with the teacher in charge of the project, Tomás Crowder, and documentary analysis. The results show that through different hypertextual resources and multi-layered editing, an interactive transmedia product is achieved that offers a journey through the 30-year history of the Escuela Internacional de Cine y Televisión de San Antonio de los Baños. Metáfora Viva, through different menus and complementary content, offers viewers the opportunity to configure their own non-fiction audiovisual consumption experience.

KEYWORDS

Interactive documentary; Webdoc; Transmedia; Latin America; Cuba; EICTV. 


\section{Documental interactiu i transmèdia a Amèrica Llatina. L'Escuela Internacional de Cine y Televisión de San Antonio de los Baños (Cuba) a través del cas de Metáfora Viva}

\section{RESUM}

Aquest estudi de cas sobre el documental interactiu Metáfora Viva, 30 años de orden y caos analitza la transmedialitat i la interactivitat del projecte $i$ aprofundeix en el seu procés creatiu i de producció, en les estratègies narratives i en els trets que l'uneixen a la resta de producció documental interactiva realitzada actualment a Llatinoamèrica. S'ha utilitzat un enfocament qualitatiu basat en l'anàlisi de la peça audiovisual, l'entrevista en profunditat al professor a càrrec del projecte, Tomás Crowder, $\mathrm{i}$ l'anàlisi documental. Els resultats mostren com a través de diferents recursos hipertextuals i amb l'ús del muntatge en múltiples capes, s'aconsegueix un producte transmèdia interactiu que ofereix un recorregut pels 30 anys d'història de l'Escuela Internacional de Cine y Televisión de San Antonio de los Baños. Metáfora Viva, a través de diferents menús i continguts complementaris, ofereix a l'espectador l'oportunitat de configurar una experiència pròpia de consum audiovisual de no ficció.

\section{PARAULES CLAU}

Documental interactiu;Webdoc; Transmèdia; Llatinoamèrica; Cuba; EICTV.

\section{Introducción y estado de la cuestión}

\subsection{La no ficción interactiva}

El proceso de convergencia (Jenkins, 2006; Gershon, 2016), provocado por el auge y expansión de Internet, ha supuesto la aparición de un nuevo ecosistema mediático (Canavilhas, 2011, 2015) caracterizado por la hibridación de medios, géneros, formatos y soportes. Dicho paradigma comunicativo constituye la plasmación de dos vaticinios: la "sociedad red" de Castells (2001) y el cambio de posición del usuario de los medios, antes pasivo, hasta convertirse en un sujeto activo de la comunicación generador de contenidos -o prosumer (Toffler, 1980)- con el surgimiento de la Web 2.0. Entre todas estas nuevas propuestas narrativas, Gifreu-Castells (2015) define la no ficción interactiva como un macrogénero que comprende todas las formas de lo real adaptadas al medio interactivo y que emplea los recursos de los medios digitales: hipertextualidad, multimedialidad e interactividad. De este modo, se procura proporcionar una imagen fidedigna de la realidad para que esa audiencia activa construya su propia narrativa a través de la inmersión y de la experiencia individual.

Por tanto, se puede definir el documental interactivo "como una forma del género de no ficción interactiva caracterizada por la representación de lo real a través de un medio interactivo" (Vázquez-Herrero, Negreira-Rey y Pereira-Fariña, 2017, p. 399). Estos autores efectúan también una recopilación de las diferentes denominaciones que ha recibido este tipo de documental: webdoc o documental web (Nash, 2012), documental multimedia interactivo (Rodríguez y Molpeceres, 2013), documental transmedia (Porto Renó, 2013), I-doc (Aston y Gaudenzi, 2012; Gantier y Labour, 2015), living documentary (Gaudenzi, 2013) o collab docs (Dovey y Rose, 2012) y, finalmente, documental interactivo (Almeida y Alvelos, 2010; Gifreu-Castells, 2013; Miles, 2014; Nash, 2014; Liuzzi, 2015). Asimismo, incluyen en su estudio dos clasificaciones de documental interactivo: una basada en la experiencia del usuario (Gaudenzi, 2013) para construir cuatro modos de interacción -conversacional, hipertextual, participativo y experiencial-. La otra, propuesta por Gifreu-Castells (2013), que diferencia varias modalidades de navegación - partida, temporal, espacial, testimonial, ramificada, hipertextual, preferencial, audiovisual, sonora y simulada-inmersiva-; la combinación de las mismas da como resultado unos productos audiovisuales e interactivos complejos. Con ello, se certifica "la ruptura de unidireccionalidad y la autoría compartida, favorecida por una nueva relación entre el autor, el relato y el usuario" (Vázquez-Herrero y López-García, 2018, p. 33). De esta forma, se establece

una nueva relación autor-texto-usuario, que supone una pérdida de control por parte del creador o una autoría compartida (Gifreu, 2013; Nash, 2012; Favero, 2013), la toma de decisiones (O'Flynn, 2012) y el rol activo del usuario (Aston y Gaudenzi, 2012). De esa relación surgen los 
nuevos compromisos de la audiencia (Nash, 2012), una pieza fundamental para el desarrollo del relato interactivo y su expansión. (Vázquez-Herrero, Negreira-Rey y Pereira-Fariña, 2017, p. 399)

Esta conceptualización del documental interactivo la completan Gifreu-Castells, Sánchez-Castillo y Galán (2019) con la consideración de este como un formato nativo transmedia en el que "la narrativa transmedia encuentra un potente aliado, pues este permite una expansión del relato no tan compleja a la hora de jerarquizar el contenido y generar coherencia entre las diferentes plataformas, como puede ejercer la ficción" (p. 281). Esta parte de la definición de documental interactivo deriva directamente de otros dos conceptos: en primer término el de transmedia, descrito por Scolari (2014) como "un relato que se cuenta a través de medios y plataformas" y en el que "una parte de los receptores no se limita a consumir el producto cultural, sino que se embarca en la tarea de ampliar el mundo narrativo con nuevas piezas textuales" (p. 72); en segundo lugar, el de universo narrativo transmedia enunciado por Irigaray (2016): "es un espacio específico alrededor del que convergen diversos medios representando distintos aspectos de él" (p. 41). Lovato (2014) aporta dos rasgos característicos que determinan la narratividad, la experiencia del usuario y la cuestión de la autoría en este tipo de proyectos:

Hipertextualidad y montaje multicapas son, entonces, condiciones particulares de los DMI (documental multimedia interactivo), donde es preciso, además, focalizar la producción en usabilidad de las piezas. La navegación hipertextual permite una composición abierta, que no acaba en el producto puesto en línea, sino que se reinicia en cada nuevo recorrido, en cada nueva lectura, en cada nueva interacción. Muchos autores vieron temblar allí las estructuras del autor-dueño de la obra, pieza determinante de la verdad del relato. Sin embargo, los DMI tienen potencial de polifonía: pueden hacer sonar varias voces en simultáneo, mostrar diferentes aristas de los hechos y expandir las posibilidades del sentido. (p. 55)

Como hemos comentado al inicio, el documental interactivo se ha desarrollado en las últimas décadas gracias a los avances tecnológicos y a la convergencia tanto de medios como de dispositivos, que han comportado el florecimiento en paralelo de las narrativas transmedia (Liuzzi, 2015). Coincidiendo con los argumentos de Aston, Gaudenzi y Rose (2017), el i-doc se enfrentará en el futuro inmediato a nuevos retos tecnológicos y a un ecosistema social, político y cultural en constante transformación. Así, algunos de los desafíos a los que se enfrenta el documental interactivo son, entre otros, lograr la implicación y proactividad de los espectadores para extender los tiempos de visionado o la adecuada implementación de los avances tecnológicos para enriquecer la narrativa de los proyectos y aumentar su capacidad inmersiva. Sin embargo, este crecimiento no ha conllevado su producción en masa a escala mundial (Vázquez-Herrero y Moreno, 2017), aunque formatos de no ficción interactiva ya hayan sido premiados en certámenes de reconocido prestigio, como los Premios Ondas y los World Press Photo (El País, 7 de octubre de 2021; EFE, 15 de octubre de 2021).

\subsection{El documental interactivo latinoamericano}

En el ámbito latinoamericano, en cambio, la producción de documentales interactivos y transmedia ha alcanzado dimensiones considerables por una serie de factores enumerados por Gifreu-Castells (2017): una lengua común, una realización efectuada desde el punto de vista emocional, su potencial para interconectar diferentes proyectos locales entre sí y las oportunidades que proporciona para representar determinadas realidades sociales e históricas. La producción documental en este ámbito geográfico y cultural es tal que Calvo (2019) se cuestionaba en su investigación si podríamos hablar de un cine documental latinoamericano con características propias, llegando a la conclusión de que "se desarrolla en un contexto social, económico y político con una serie de rasgos comunes que permiten [...] tomar la región como ámbito geográfico de estudio" (p. 128). La preocupación del documental interactivo, y especialmente del latinoamericano, por lo social va más allá de la simple representación o análisis y busca una "intervención sobre la realidad" (Guardia, 2013, p. 271).

Todo ello se ha traducido en una larga serie de títulos latinoamericanos contemporáneos. En el artículo ya mencionado de Vázquez-Herrero y Moreno (2017) se identifican los siguientes en el periodo 2013-2017: 0 responsables (España, 2013), El charco azul (Colombia, 2013), Calles perdidas (Argentina, 2013), Chaco-PY (Paraguay, 2014), Illados (España, 2014), 4 ríos (Colombia, 2014), Proyecto Quipu (Chile-Perú-Reino Unido, 2015), Pregoneros de Medellín (Colombia, 2015), Canción de la ciudad (Argentina, 2015), Mujeres en venta (Argentina, 2015), Desiguales (Argentina, 2016) - de estos dos proyectos argentinos realiza un análisis crítico Durr-Missau (2016) - y El feriante (Argentina, 2017).

La más reciente investigación de Costa-Sánchez y López-García (2021) recoge una muestra de 25 proyectos transmedia de carácter social (todos ellos incluyen documental) en el quinquenio 2014-2018 -aunque algunos aún se encuentran en desarrollo-, entre los que se hallan algunos de los ya citados. Los demás son Aylan Project (España, 2015), En negro contra as violencias (España, 2015), Las Sin sombrero (España, 2015), Tras los muros (México, 2015), La tierra sin tierra (España, 2016), Lata de Sardinas (España, 2016), Proyecto hambre (España, 2016), Invisibles (España, 2017), Primavera rosa (España, 2017), Ni una menos (Argentina, 2017), Idrissa (España, 2018), Por el clima (España, 2018), Susi, una elefanta en la habitación (España, 2018), Barnacas (España, 2018-2020), Colombianas: una biografía colectiva (Colombia, 2018), Crónicas elefantiles (Colombia, 2018), Transformacciones (Colombia, 2018), La otra orilla (Colombia, 2018), De barrio 
somos (Argentina, 2018) y Mujeres ingenieras (Argentina, 2018).

Por su parte, el estudio de Torres-Martín (2019) también menciona otras obras como Desarmados (2017) y La memoria de los peces (2018), ambas colombianas. Este país es prolífico en este tipo de filmografía, con Paciente (2015) como otro ejemplo relevante (Bouchet y Caballero, 2017). Arévalo (2021) destaca otras producciones como Som dos Sinos (Brasil, 2014), Momento Mx (México, 2015), Wi-five (Cuba, 2016) y Proyecto Walsh (Argentina, 2018). Gifreu-Castells, Sánchez-Castillo y Galán (2019) y Cruz (2019, en entrevista al propio Gifreu-Castells) completan este listado con los documentales españoles Cromosoma 5 (2013), Bugarach. Cómo sobrevivir al Apocalipsis (2016), Sexo, maracas y chiuauas (2016), el brasileño Autorretrato (2011), el mexicano La geografía del dolor (2014) y el cubano Metáfora Viva (2016), que será objeto de la presente investigación.

Metáfora viva es un webdoc interactivo creado en el IDOC (Taller de Producción de Documentales Interactivos) de la Escuela Internacional de Cine y Televisión de San Antonio de los Baños (Cuba) con motivo del trigésimo aniversario de dicha institución.

\section{Objetivos y metodología}

El objetivo general de este trabajo se centra en estudiar la transmedialidad y la interactividad del proyecto Metáfora viva. Para ello, se fijan como objetivos secundarios:

- Determinar cuál ha sido el proceso creativo y de producción audiovisual del webdoc.

- Conocer el equipo técnico y artístico que ha intervenido en su elaboración.

- Analizar las estrategias interactivas y transmedia a nivel técnico, discursivo y de contenido.

- Identificar algunos de los rasgos comunes que lo unen al resto de producción documental interactiva realizada en Latinoamérica en la actualidad.

Esta investigación se fundamenta en un estudio de caso sobre el documental interactivo Metáfora Viva, 30 años de orden y caos. Para realizarlo, seguiremos el esquema construido por Gifreu-Castells, Sánchez-Castillo y Galán (2019), cuya estructura se sustenta sobre cinco pilares:

- Descripción del tema y de la narratividad del proyecto.

- Desarrollo, producción y distribución, es decir, efectuar un repaso por las diferentes etapas del proceso industrial del producto audiovisual.

- Determinar las funciones clave que han desempeñado cada uno de los miembros del equipo humano implicado en la realización del documental.

- Plataforma-estructura: describir cómo es la web donde está alojado el webdoc, que en este caso actúa como lanzadera del resto de contenidos interactivos.

- Resultados y retos del futuro: analizar los datos obtenidos en el estudio y sugerir ideas de mejora que puedan servir para proyectos venideros.

Como técnicas complementarias de recolección de datos, se han empleado:

- La revisión bibliográfica documental (Del Río y Velázquez, 2005), que se ha aplicado en la construcción del marco teórico, así como para fundamentar el diseño metodológico del trabajo y las categorías analíticas utilizadas en su desarrollo.

- La entrevista en profundidad (Wimmer y Dominick, 1996), utilizada con el objetivo de conocer la experiencia personal del principal artífice del proyecto.

Para identificar y analizar las funciones de los miembros del equipo se diseñó una rúbrica específica que abarcase los puestos técnicos implicados en la producción (tabla 1)

\begin{tabular}{|l|l|}
\hline \multirow{4}{*}{ Conceptualización } & Ideación \\
\cline { 2 - 2 } & Profesorado implicado \\
\cline { 2 - 3 } & Coordinación \\
\cline { 2 - 3 } & Asesoría \\
\hline & Producción y producción ejecutiva \\
\hline \multirow{2}{*}{ Puestos técnicos } & Distribución \\
\hline & Cámara \\
\hline & Gaffer \\
\hline & Fotografía y foto fija \\
\hline & Edición y microfonía \\
\hline & Diseño y diseño web \\
\hline & Postproducción audio y vídeo \\
\hline
\end{tabular}

Tabla 1. Rúbrica de análisis de las funciones del equipo. Fuente: elaboración propia

\section{Resultados}

\subsection{Tema y narratividad del proyecto}

Metáfora viva, 30 años de orden y caos aborda, con motivo de su $30^{\circ}$ aniversario, la historia y producción de la Escuela Internacional de Cine y Televisión de San Antonio de los Baños, en Cuba, entre 1986 y 2016. El objetivo del documental interactivo 


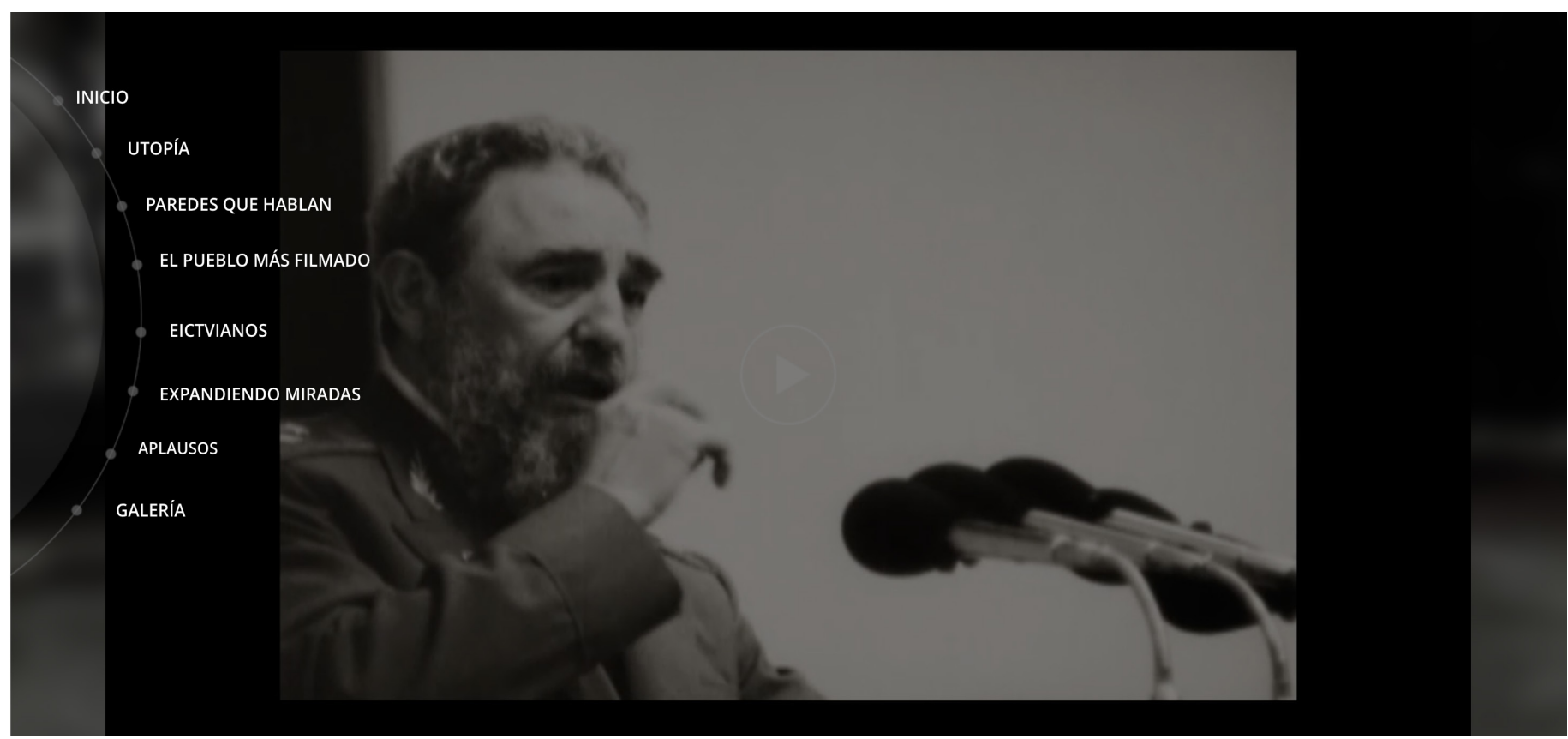

Figura 1. Menú general de navegación de Metáfora Viva. Fuente: web de Metáfora Viva.

es aprovechar las posibilidades narrativas que ofrece este formato para ofrecer una completa perspectiva sobre la Escuela, de modo que la producción pudiera abarcar no solo su historia, sino también su filosofía y el modo de enfocar el aprendizaje a través de su modelo de enseñanza, los vínculos con las personas que la conforman o que han pasado por ella y los lazos que ha establecido con la comunidad donde se enclava, así como la relación con el cine y con la propia Cuba.

Tomás Crowder, polifacético y prolífico cineasta, periodista, productor de eventos y creador de revistas y comunidades online, es además profesor tanto en la Universidad de Buenos Aires como en la EICTV. Dada su responsabilidad en esta última institución como docente de Nuevos Medios y encargado del taller de IDOC (documental interactivo), fue el tutor del alumnado que realizó Metáfora Viva. Asegura que este proyecto fue una idea conjunta de los responsables de la escuela y los miembros del propio taller, al considerarlo "una posibilidad única de dar a conocer, preservar y poder tener online para futuros estudiantes y/o público en general, parte importante del increíble acervo audiovisual con el que cuenta la Escuela tras sus primeros 30 años" (Crowder, comunicación personal, 5 de julio de 2021).

El documentalista, autor de obras galardonadas como Surfing Favela (2005) o El otro Ché (2010), alude al lema de la Escuela Internacional de Cine y Televisión para describir cómo fue el proceso creativo de este webdoc: "Aprender haciendo".

Bajo este concepto nos largamos (sic) a una aventura de proporciones épicas. La escuela me permitió el desafío de llevar adelante la cátedra o curso más extenso en días hasta la fecha (30 días de clases seguidos), sumado a que contábamos con cientos de horas de material para revisar de una escuela que destila historia. (Crowder, comunicación personal, 5 de julio de 2021)

Este proceso tuvo lugar, además, en un momento de especial trascendencia histórica para la entidad, puesto que durante el mismo "dejaban de existir físicamente personas muy importantes en la historia de la Escuela como Ettore Scola, Abbas Kiarostami y hasta su fundador, el mismísimo comandante Fidel Castro" (Crowder, comunicación personal, 5 de julio de 2021). Crowder, desde su nuevo cargo como Secretario de Turismo, Cultura y Deporte en la ciudad de Miramar (Argentina), asevera que esta empresa intentó ser un compendio de la producción de la EICTV, "incluyendo producciones de sus alumnos, el proyecto de cine rural comunitario de la Sierra Maestra, una retrospectiva de algunos de sus personajes más entrañables, entre otros, desarrollando también producciones locales acordes al subtítulo de nuestro I-Doc: 30 años de orden y caos" (Crowder, comunicación personal, 5 de julio de 2021).

En la práctica, la web actúa de repositorio de los proyectos más señeros producidos en el seno de la EICTV durante sus treinta años de existencia y en ella tiene cabida todo tipo de material interactivo multimedia (fragmentos de otros documentales, vídeos, fotografías, textos, galardones obtenidos por las distintas obras, etc.). Abarca desde los testimonios de los fundadores de la EICTV, estudiantes que han pasado por la escuela o profesorado, hasta las grandes figuras del cine que la visitaron, algunas de sus producciones más exitosas o la relación con su entorno. La narratividad está planteada a través de una estructura aparentemente lineal pero que, a su vez, se complementa con contenido alternativo jerarquizado en secciones relacionadas, a las que se accede conforme avanza el visionado y que permiten decidir el orden de consumo del 
material audiovisual.

De este modo, a medida que el espectador avanza en la visualización del documental van apareciendo diferentes indicadores que, al pinchar sobre ellos, despliegan un menú circular de acceso a nuevos elementos y cápsulas (figura 1). Tras interactuar con estos elementos es posible retomar la reproducción donde se había pausado, así como avanzar o retroceder en ella.

La estructura narrativa del documental central, Metáfora viva, 30 años de orden y caos, se sustenta en distintas declaraciones del personal fundador de la Escuela, así como de antiguos alumnos y alumnas de la misma. El hilo conductor es mínimo, pero tanto en el inicio como en el cierre se utilizan unas reflexiones de Fernando Birri, fundador de la Escuela, que giran en torno al concepto de utopía.

La realización audiovisual es sencilla, con una planificación audiovisual sustentada en la utilización del plano medio con el entrevistado o entrevistada dirigiéndose a un interlocutor detrás de la cámara. En muy escasas ocasiones se rompe esta planificación; es el caso de ligeros movimientos de cámara mediante travellings laterales y de acercamiento en los minutos 12 y 22 . Se produce también un ligero movimiento de cámara en las declaraciones de Rosa Teichmann en el minuto 10'30". También, con la intencionalidad narrativa de incidir en la importancia de las declaraciones, el último testimonio de Fernando Birri se realiza a través de un primerísimo primer plano. La cámara suele permanecer estática excepto en las declaraciones de Birri, en las que se producen ligeros movimientos acerca de su figura.

El documental no consta de banda sonora, pero algunos fragmentos de archivo, como los del minuto 14'10" incluyen música acompañando a las imágenes en vídeo de realizadores de reconocido prestigio. El material sonoro principal son las declaraciones a cámara de los entrevistados y entrevistadas y el audio que acompaña a las imágenes de archivo. Algunas de estas declaraciones presentan un registro sonoro con ciertas carencias, como es la intervención de Alquimia Peña en el minuto 1'50" o la de Susana Molina en el minuto 5'54".

\subsection{Desarrollo, producción y distribución del trabajo}

El proyecto fue creado en el IDOC (Taller de Producción de Documentales Interactivo) de la EICTV en el año 2016. El 15 diciembre de 1986 tuvo lugar la inauguración de la Escuela, por lo que la presentación de Metáfora viva se programó para el día que se conmemoraba su $30^{\circ}$ aniversario.

Para construir este documental interactivo se combinan materiales creados ex profeso para la producción con otros recursos de archivo de la Escuela y se incorporan recursos textuales, fotográficos, infográficos y animaciones, así como documentos en distintos idiomas.

\subsection{Funciones clave de los miembros del equipo humano}

El equipo humano que hizo posible el proyecto (tabla 2) estuvo formado por el alumnado de tercer año de la Cátedra de Televisión y Nuevos Medios de la EICTV y del Taller de Producción de Documentales Interactivos, por su profesor y por otros miembros de la Cátedra. En su realización colaboraron más de medio centenar de personas.

\begin{tabular}{|c|c|}
\hline Tareas y cargos & Personas \\
\hline Idea original & Janaina Moraes \\
\hline Producción Ejecutiva & $\begin{array}{l}\text { Ana Luisa Sánchez, Eddy Gamboa, } \\
\text { Jade Azevedo, Janaina Moraes, Keni- } \\
\text { tay Orsini, Maga Zevallos, Enrique } \\
\text { Fajardo Cortés y Paola Rojas }\end{array}$ \\
\hline Profesor a cargo & Tomás Crowder \\
\hline Jefe de Cátedra & Rigoberto Jiménez y Fabián Zampedri \\
\hline Coordinador & Luis Abel Oliveros \\
\hline Asesoría & Arnau Gifreu \\
\hline $\begin{array}{l}\text { Financiación y } \\
\text { diseño de distribu- } \\
\text { ción }\end{array}$ & $\begin{array}{l}\text { Carolina Graterol, Yamila Marerro, } \\
\text { Maricarmen Castill Abrego, Víctor } \\
\text { Santillán, Xochil Vergara, María Fer- } \\
\text { nanda Carvajal }\end{array}$ \\
\hline Producción & Marlén Ruiz \\
\hline Cámara & Yoanny Oliva \\
\hline Dollyman & Ihosvany Zumeta \\
\hline Gaffer & Mijan David Sánchez \\
\hline Fotografía Italia & Lorenzo Casadio \\
\hline Foto Fija & Tiago Pedro \\
\hline $\begin{array}{l}\text { Sonido Directo y } \\
\text { Postproducción de } \\
\text { sonido }\end{array}$ & Alan Mairena Flores \\
\hline Microfonista & Rafael González \\
\hline Edición & Emmanuel Peña, Ariadna Liz Pimentel \\
\hline Postcolor & $\begin{array}{l}\text { Nancy Angulo, Emmanuel Peña, } \\
\text { Ariadna Liz Pimentel }\end{array}$ \\
\hline Diseño & $\begin{array}{l}\text { Kevin Humberto García Gandía, Javier } \\
\text { Guillén Miranda, Enrique Fajardo } \\
\text { Cortés }\end{array}$ \\
\hline $\begin{array}{l}\text { Postproducción } \\
\text { material de archivo }\end{array}$ & $\begin{array}{l}\text { Enrique Fajardo Cortés, Paola Rojas, } \\
\text { Kenitay Orsini, Janaina Moraes }\end{array}$ \\
\hline Desarrollo web & Jandy Gómez, Kenitai Orsini \\
\hline Diseño de créditos & Enrique Fajardo Cortés \\
\hline Webmaster & Mario Mayor Ibarra \\
\hline
\end{tabular}

Tabla 2. Créditos de Metáfora Viva. Fuente: elaboración propia.

Así, Metáfora Viva "fue enteramente realizado por los alumnos de tercer año de la Cátedra de Televisión y Nuevos Medios de la EICTV" (Crowder, 5 de julio de 2021). El tutor, por su parte, ejerció la dirección y la producción general de este documental interactivo. Asimismo, destaca la contribución como asesor de Arnau Gifreu-Castells, que aportó "mucho conocimiento y trabajo dentro del área de I-Doc y Nuevos Medios, a quien introduje en la familia EICTViana (sic) e hice que se sumara a la 
currícula de profesores de la escuela" (Crowder, comunicación personal, 5 de julio de 2021). Para el proyecto se contrató a dos diseñadores y un programador, cuyo desempeño es valorado como crucial por nuestro entrevistado:

Debemos recordar las limitaciones técnicas y tecnológicas que existen en la isla; por eso valoro la dedicación de Jandy, Kevin, Javier y quien ayudara a ambos, Enrique, para lograr una interfaz simple pero poderosa donde, a través de la programación y diseño, resumimos la enorme cantidad de material que teníamos para compartir. (Crowder, comunicación personal, 5 de julio de 2021)

Estas dificultades de índole técnica provocaron que los participantes en el proyecto tuvieran que agudizar su ingenio: "la diferencia con otros documentales interactivos/transmedia se basó prácticamente en que en la isla no contamos con buena conectividad [...] debíamos repensar a cada minuto como poder llevar adelante el I-doc sin ralentizar el ambicioso proceso de producción" (Crowder, comunicación personal, 5 de julio de 2021).

En los primeros días del taller se llevaron a cabo la ideación, la guionización y la preproducción de la obra. Posteriormente, el plan de trabajo transcurrió en los siguientes tiempos:

En la segunda semana salimos con algunos alumnos a realizar los proyectos y segmentos, mientras con los restantes revisábamos material de los últimos 30 años de la EICTV. En la tercera sumamos el trabajo de los diseñadores y el programador del Klynt, las filmaciones que tuvimos que reprogramar o realizar fuera de la Escuela en La Habana, y en la cuarta comenzamos la transmutación de todo este trabajo para lograr la magia de tener para la celebración oficial de la EICTV los últimos 30 años en 30 días de trabajo donde un grupo enorme de personas dejaron todo para alcanzar este logro colectivo. (Crowder, comunicación personal, 5 de julio de 2021)

La labor de tutela del propio Crowder se fundamentó, en sus propias palabras, en desdramatizar ante su alumnado el proceso de creación audiovisual: "Werner Herzog o Quentin Tarantino, que sin haber estudiado como lo están haciendo esos alumnos, han encontrado la forma de materializar que contar historias hoy prácticamente lo puede hacer cualquier ser humano" (comunicación personal, 5 de julio de 2021). A esto añade el factor de la accesibilidad de la tecnología: "les comparto el ejemplo de la película Tangerine, de Sean Baker, filmada con un Iphone 5, suceso del Sundance Film Festival [...] logrando una taquilla 10 veces más grande que su presupuesto original" (Crowder, comunicación personal, 5 de julio de 2021). Por último, acude de nuevo al vector tecnológico para hablarnos de las nuevas posibilidades en cuanto a expansión de los productos audiovisuales: "programas/plataformas muy accesibles como Klynt y Korsakow, y otras en desarrollo que permiten que nuestras historias queden subidas a internet y puedan ser vistas en todo el mundo" (Crowder, comunicación personal, 5 de julio de 2021).

Respecto al rodaje, apenas se contó con "una unidad básica de dos cámaras, sonidista y productor" (Crowder, comunicación personal, 5 de julio de 2021). El profesor actuó en el mismo como "entrevistador detrás de cámara en formato de set natural para permitir la interacción lo más realista posible con el entrevistado" (Crowder, comunicación personal, 5 de julio de 2021). En total, todas las fases del proceso de producción audiovisual, es decir, "guion, rodaje, edición y posproducción lo realizamos en 15-17 días, jcontrarreloj!" (Crowder, comunicación personal, 5 de julio de 2021). En cuanto a la promoción, "utilizamos los medios que tiene el ICAIC, la televisión y prensa nacional cubana para difundir nuestro proyecto y pudimos

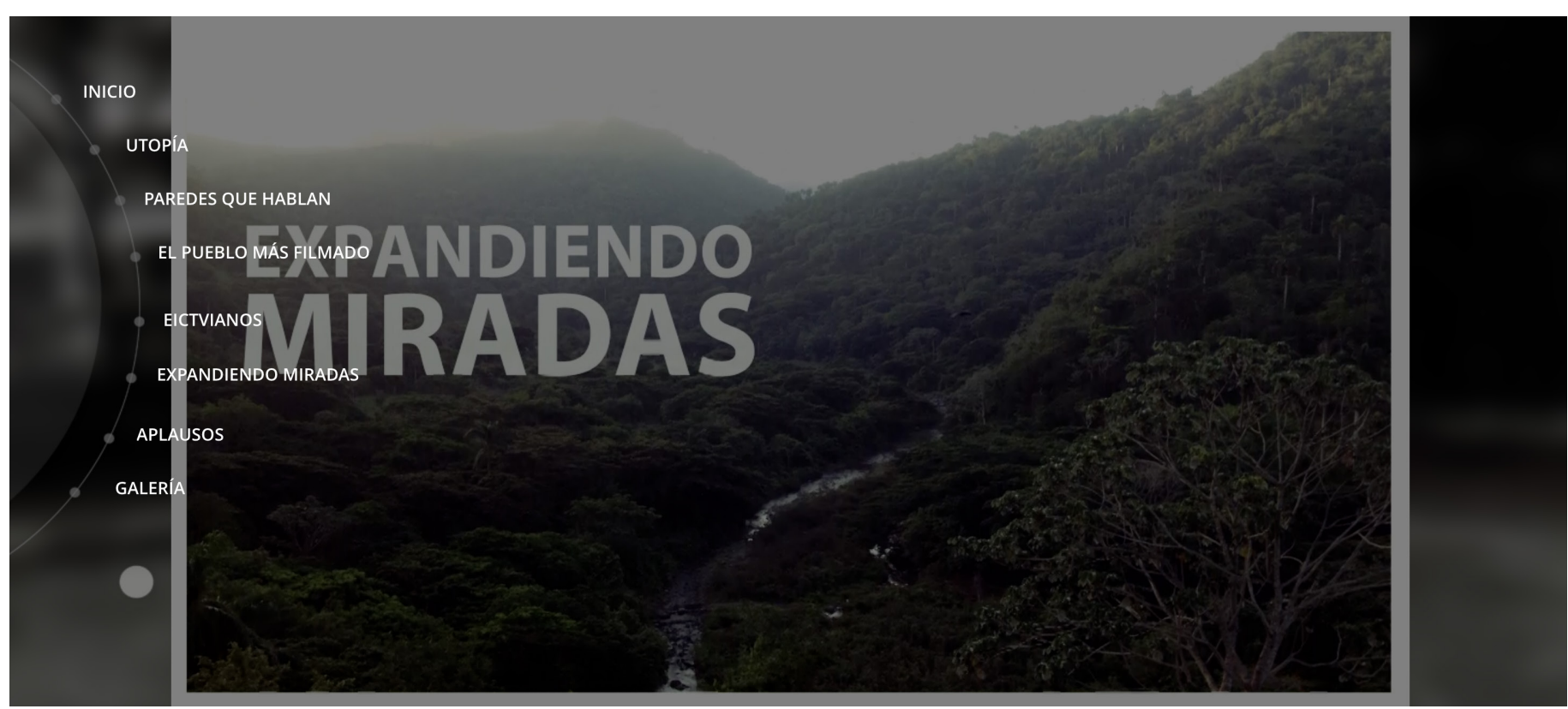

Figura 2. Menú general de navegación de Metáfora Viva. Fuente: web de Metáfora Viva. 


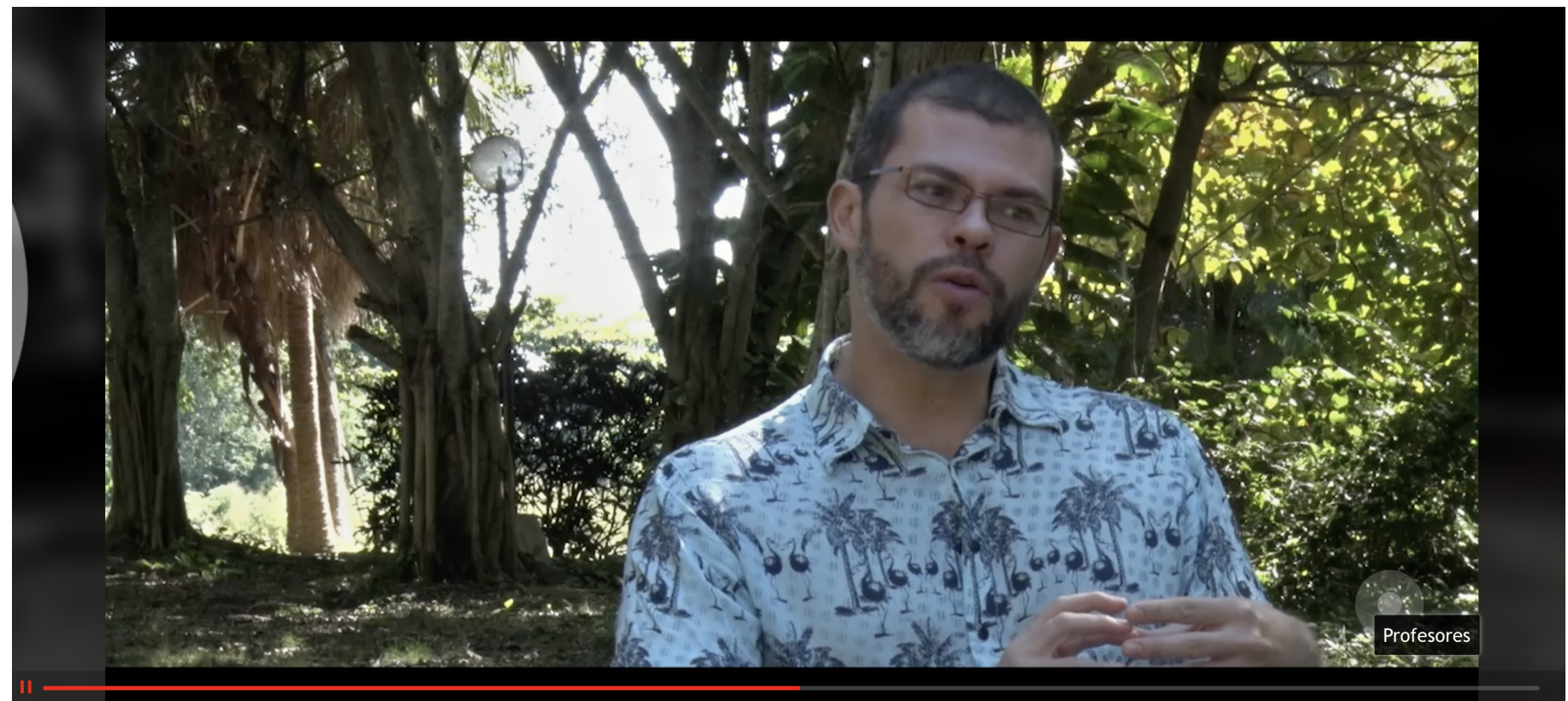

Figura 3. Indicador en pantalla de la presencia de un menú interactivo. Fuente: web de Metáfora Viva.

presentarlo para una importante audiencia nacional e internacional" (Crowder, comunicación personal, 5 de julio de 2021).

\subsection{Plataforma-estructura del proyecto}

El proyecto cuenta con 7 secciones diferentes que disponen de menús dependientes; estos albergan cápsulas breves para que el espectador amplíe la información según sus intereses. A estas secciones principales se puede acceder en todo momento a través de un menú general con forma de arco que se despliega al pinchar en la parte izquierda de la pantalla (figura 2)

Cada una de estas secciones contiene a su vez diferentes menús circulares a los que también se accede desde la pan- talla principal mediante un pequeño círculo parpadeante sobreimpresionado en la parte inferior derecha de la imagen (figura 3).

Una vez que se clica en él se inicia una nueva sección a través de la cual se puede navegar empleando el menú circular inferior, que también permite avanzar o retroceder hacia otras secciones (figura 4).

Además de estos esquemas circulares, algunas secciones contienen menús superiores y parrillas con contenido desplegable e hipervínculos que dan acceso a nuevas píldoras y elementos extra (figura 5).

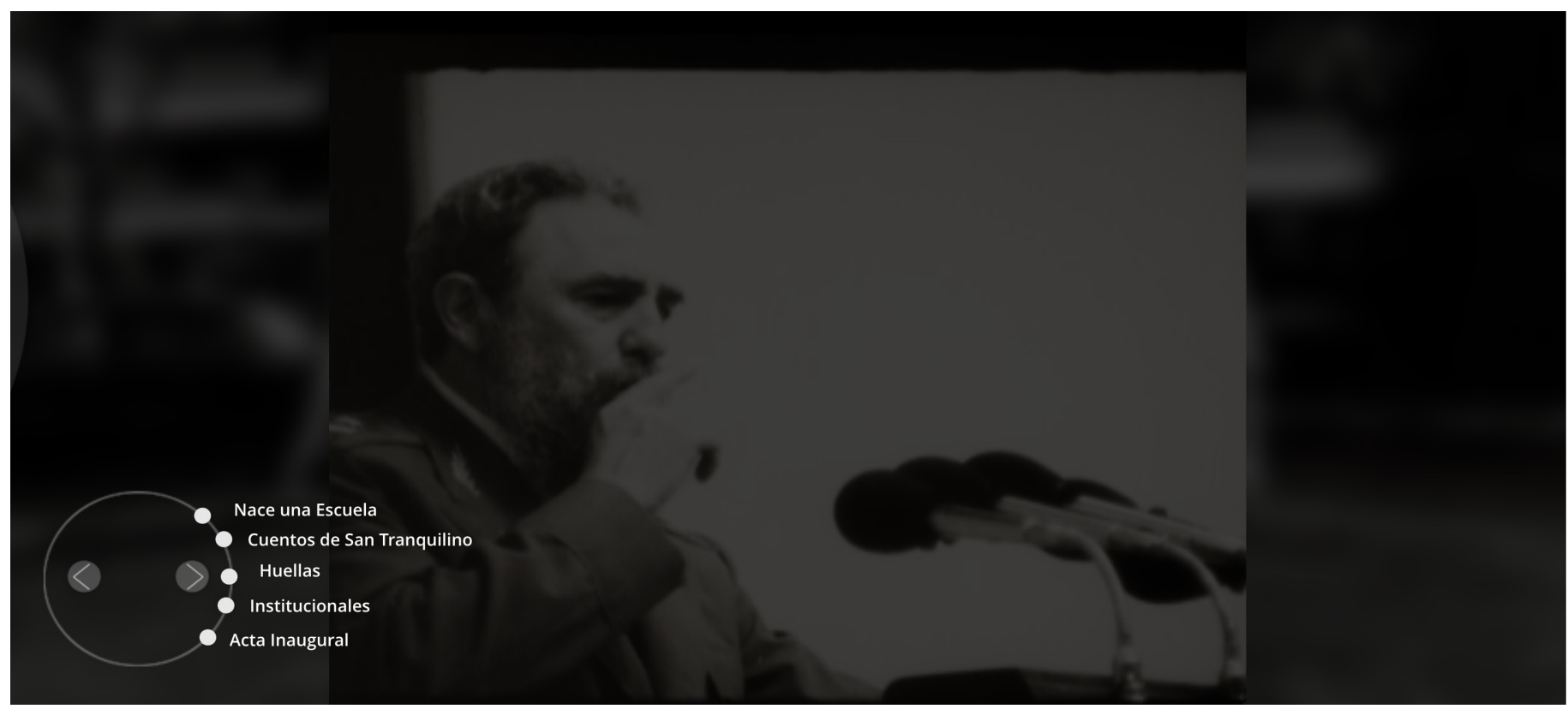

Figura 4. Menú de sección con acceso a los contenidos y píldoras. Fuente: web de Metáfora Viva. 


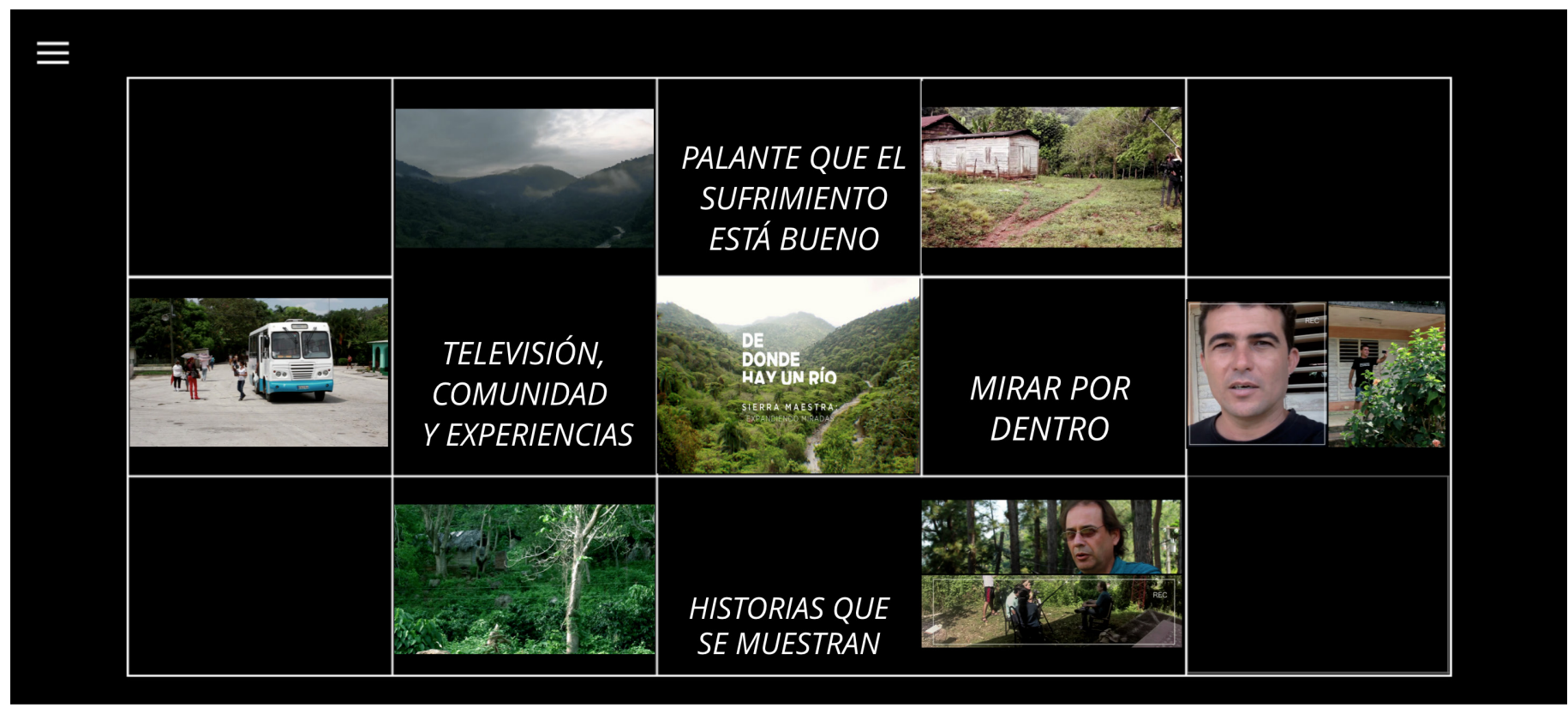

Figura 5. Ejemplo de submenú de navegación. Fuente: web de Metáfora Viva.

De forma general, el esquema narrativo de este documental interactivo se configura del siguiente modo:

- Utopía: Historia de EICTV

Nace una escuela
Cuentos de San Tranquilino
Huellas
Institucionales
Acta inaugural

- Paredes Que Hablan: Visitantes ilustres

- El Pueblo más Filmado: San Antonio de los Baños y su relación con la EICTV

Luces, cámara y acción

El pueblo más filmado

Fuera de la pecera

- Eictivianos: comunidad que conforma la EICTV
Alumnos
Profesores
Trabajadores
Mascotas

- Expandiendo Miradas: televisión Serrana y su relación con la EICTV

De donde hay un río

One to one

- Aplausos: Reconocimientos y Premios EICTV

- Galería: Identidad EICTV

Homenaje a Ovidio

Galería

Así, la estructura de Metáfora Viva permite conocer de forma interactiva los diferentes aspectos que han conformado la EICTV a lo largo de sus 30 años de historia al combinar diferentes tipos de documentos que posibilitan al espectador decidir el orden en que quiere acceder a ellos y el tiempo que desea dedicar a su visionado y lectura, pues la duración de las píldoras es variable.

En cuanto a la plataforma en que se desarrolló el trabajo, hay que tener presente que las limitaciones técnicas y tecnológicas que existen en Cuba fueron un factor relevante en la propia configuración del proyecto, que empleó el software Klynt para su desarrollo.

El cineasta argentino, organizador también de la "Sección Ventana" dentro del Festival Internacional de Cine de Mar del Plata, confirma la apuesta tanto de la escuela como de su Cátedra de Televisión y Nuevos Medios por este tipo de textos audiovisuales: "ya incursionan, desde sus ejercicios docentes, en este perfil de formato narrativo y de indiscutible interactividad. Lo hacen tratando de encontrar en ella una manera diferente de contar nuestra realidad" (Crowder, comunicación personal, 5 de julio de 2021). A continuación, pasa a establecer una definición de dicho formato:

Instrumento de comunicación que aporta múltiples aspectos sobre nuestra historia y la realidad circundante. La curiosidad, la libertad, la búsqueda y el hallazgo distinguen al documental interactivo. Una expresión genérica que no limita al usuario, pues este navega e, incluso, entra y sale de la plataforma comunicativa según sus necesidades e intereses. Lo que se persigue es propiciar estructuras multidesarrollos que contemplen diferentes recorridos y desenlaces. (Crowder, comunicación personal, 5 de julio de 2021)

De igual forma, lo confronta con los documentales convencionales: "en un documental tradicional se nos impone una mirada, un relato que empieza y termina linealmente, que puede tener varias aristas e historias dentro de ese relato, pero que lleva al espectador desde el punto $A$ al punto $B$ de la 
mano y donde la interacción está prohibida" (Crowder, comunicación personal, 5 de julio de 2021). En conclusión, "Los nuevos formatos nos ayudan a sacar al espectador de la postura pasiva en la que se mantuvo en los últimos años, e invitan al mismo a interactuar, pensar y consumir el contenido/historia que más le plazca, creando su propia experiencia en este nuevo universo/aventura audiovisual" (Crowder, comunicación personal, 5 de julio de 2021).

\section{Discusión y conclusiones}

Siguiendo a Gifreu-Castells (2015), este trabajo combina recursos hipertextuales y multimedia con interactividad para configurarse como una pieza de no ficción interactiva. En ella se rompe la unidireccionalidad narrativa para dar paso a una autoría compartida, coincidiendo con lo expuesto en investigaciones previas sobre el documental interactivo (Vázquez-Herrero y López-García, 2018). De este modo, los distintos contenidos que conforman este webdoc -como vídeos, cartelería, fotografías o textos- se organizan conforme a un diagrama narrativo que trasciende una aparente linealidad inicial, que también se presenta como una opción totalmente válida, para dar paso a un amplio abanico de visionados posibles en los que el espectador se erige protagonista de su propia lectura audiovisual al decidir no sólo el orden, sino también la profundidad de la experiencia interactiva.

Metáfora Viva se presenta como un relato que aúna múltiples testimonios y documentos y en el que, retomando a Lovato (2014), el montaje multicapa permite combinar de forma orgánica distintas perspectivas sobre la EICTV para ofrecer una completa panorámica de sus 30 años de historia. Por otra parte, constituye una muestra de que, incluso en unas condiciones de producción adversas y sin contar con una amplia experiencia previa, es posible desarrollar documentales interactivos si se plantea la diagramación de la interactividad y la concepción narrativa de los contenidos teniendo en cuenta las limitaciones técnicas propias del proyecto.

Este trabajo alcanza sus objetivos al profundizar en la transmedialidad y la interactividad del proyecto Metáfora viva, determinando el modo en que se ha desarrollado su proceso creativo y de producción, identificando las responsabilidades del equipo técnico y creativo que lo hizo posible y analizando las diferentes estrategias que emplea para lograr la interactividad y la transmedialidad. Además, el estudio identifica algunos rasgos que unen este webdoc con el resto de producción documental interactiva realizada en Latinoamérica en la actualidad. De hecho, este proyecto reúne todos los puntos expuestos por Gifreu-Castells (2017) como característicos del documental interactivo y transmedia latinoamericano: una lengua común, realización desde el punto de vista emocional, potencial para interconectar diferentes proyectos locales entre sí y las oportunidades para representar determinadas realidades sociales e históricas. No en vano, "cabe recordar que la EICTV es la escuela que da inicio al movimiento del Nuevo Cine Latinoamericano" (Crowder, comunicación personal, 5 de julio de 2021).

Al tratarse de un estudio de caso, sus limitaciones son las propias de este diseño metodológico. No obstante, el análisis de Metáfora viva permite conocer los modos de producción y las características de una experiencia interactiva exitosa en el contexto del documental transmedia latinoamericano, lo que puede resultar de utilidad tanto en el plano académico como en el profesional. Por otro lado, se trata de un objeto de estudio de gran interés, no solo dada la prolífica producción que se ha desarrollado en los últimos años en este ámbito, sino por las posibilidades que ofrece para visibilizar los proyectos audiovisuales de producción hispanohablante. En este sentido se abre un variado abanico de futuras líneas de investigación que pueden abordar, entre otras cuestiones, aspectos como la temática y la voz que prevalece en las narraciones, las estrategias de difusión y comercialización que aplican los distintos trabajos, los recursos artísticos y financieros de los que disponen o el análisis de la producción desde una perspectiva de género.

\section{Bibliografía}

Almeida, A. y Alvelos, H. (2010). An Interactive Documentary Manifesto. ICIDS'10 Proceedings of the Third Joint Conference on Interactive Digital Storytelling, 123-128. Springer-Verlag Berlin.

Arévalo, G. (2021). Latinoamérica sin ficción. Facultad Libre.

Aston, J. y Gaudenzi, S. (2012). Interactive documentary: setting the field. Studies in Documentary Film, 6(2), 125-139. https://doi. org/10.1386/sdf.6.2.125_1

Aston, J., Gaudenzi, S. y Rose, M. (Eds.). (2017). i-Docs: the evolving practices of interactive documentary. Columbia University Press.

Bouchet, O. y Caballero, J. (2017). Sistema de salud, reflexión colectiva y cine. Entrevista con Jorge Caballero, realizador del documental Paciente. Cinémas d'Amérique latine, (25), 134-143. https://doi. org/10.4000/cinelatino.4742

Calvo, P. (2019). Cine documental latinoamericano: conclusiones con base en un estudio transversal con enfoque contextual y formal de 100 películas documentales. Kepes, 16(20), 126-151. https://doi. org/10.17151/kepes.2019.16.20.6

Canavilhas, J. (2011). El nuevo ecosistema mediático. Icono comunicación (1), 13-24. http://hdl.handle.net/10115/15275

Canavilhas, J. (2015). Nuevos medios, nuevo ecosistema. El profesional de la información, 24(4), 357-362. https://doi.org/10.3145/ epi.2015.jul.01

Castells, M. (2001). The Internet Galaxy. Oxford University Press.

Corona Rodríguez, J. M. (2016). ¿Cuándo es transmedia?: discusiones sobre lo transmedia (l) de las narrativas. ICONO14. Revista científica de Comunicación y Tecnologías emergentes, 14(1), 30-48. https://doi. org/10.7195/ri14.v14i1.919

Costa-Sánchez, C. y López-García, X. (2021). Narrativas transmedia sociales en el ámbito hispanoamericano (2014-2018). Arte, Individuo 
y Sociedad, 33(1), 237-257. https://dx.doi.org/10.5209/aris.67561

Cruz, J. (20 de marzo de 2019). El boom de los documentales interactivos en América Latina. IJNet. Red Internacional de Periodistas. https://ijnet.org/es/story/el-boom-de-los-documentales-interactivos-en-am\%C3\%A9rica-latina

Del Río, O. y Velázquez, T. (2005). Planificación de la investigación en Comunicación: fases del proceso. En Berganza, R. y Ruiz San Román, J. A., Investigar en comunicación. 43-76. McGraw Hill.

Dovey, J. y Rose, M. (2012). We're happy and we know it: Documentary, data, montage. Studies in Documentary Film, 6(2), 159-173. https:// doi.org/10.1386/sdf.6.2.159_1

Durr-Missau, L. (2016). Mujeres en venta (2015) y (des) Iguales (20152016): un análisis crítico de dos propuestas de documentales transmedia. DOC On-line: Revista Digital de Cinema Documentário, (19), 171-186. https://doi.org/10.20287/doc.d19.ar5

EFE (15 de octubre de 2021). La World Press Photo 21 València retrata hechos de un año marcado por la covid, EFE. Recuperado de https:// www.efe.com/efe/comunitat-valenciana/cultura-y-ocio/la-worldpress-photo-21-valencia-retrata-hechos-de-un-ano-marcado-porcovid/50000884-4653069

El País (7 de octubre de 2021). PRISA Audio y Cadena SER lanzan los Premios Ondas Globales del Podcast, El País. Recuperado de https:// elpais.com/comunicacion/2021-10-07/prisa-audio-y-cadena-serlanzan-los-premios-ondas-globales-del-podcast.html

Gantier, S. y Labour, M. (2015). User Empowerment and the I-Doc Model User. En Bihanic, D. (ed.). Empowering Users Through Design: Interdisciplinary Studies \& Combined Approach for Technological Products and Services. Springer.

Gaudenzi, S. (2013). The Living Documentary: From Representing Reality to Co-Creating Reality in Digital Interactive Documentary. SAGE.

Gifreu-Castells, A. (2013). El documental interactivo como nuevo género audiovisual. Estudio de la aparición del nuevo género, aproximación a su definición y propuesta de taxonomía y de modelo de análisis a efectos de evaluación, diseño y producción. (Tesis doctoral, Universitat Pompeu Fabra, España). http://agifreu.com/interactive_ documentary/TesisArnauGifreu2012.pdf

Gifreu-Castells, A. (2015). Evolución del concepto de no ficción. Aproximación a tres formas de expresión narrativa. Obra Digital (8), 14-39. https://doi.org/10.25029/od.2015.54.8

Gifreu-Castells, A. (2017). Interactive documentary aquí y ahora here \& now: themes and directions in South America. In J. Aston, S.
Gaudenzi y M. Rose (eds.), i-Docs: the evolving practices of interactive documentary. Columbia University Press.

Gifreu-Castells, A., Sánchez-Castillo, S. y Galán, E. (2019). Aproximación al documental interactivo como formato nativo transmedia. Pasavento. Revista de Estudios Hispánicos, 7(2), 275-302. https://doi.org/10.37536/preh.2019.7.2.722

Guardia, I. (2013). La ruptura del relato en la narración transmedia: creación de espacios para la acción social. Fonseca, Journal of Communication, (6), 258-279.

Herrero, J. V. y Moreno, G. (2017). Documental interactivo iberoamericano: proximidad y transformación social. DOC On-line: Revista Digital de Cinema Documentário, 109-130. https://dog.org/10.20287/ doc.esp17.dt05

Irigaray, F. (2016). Documental Transmedia: narrativas espaciales y relatos expandidos. En F. Irigaray y D. Renó (comps.) Transmediaciones. Creatividad, innovación y estrategias en nuevas narrativas. 38-53. Crujía.

Jenkins, H. (2006). Convergence culture: where old and new media collide. New York University Press.

Liuzzi, A. (2015). El documental interactivo en la era transmedia: de géneros híbridos y nuevos códigos narrativos. Obra digital: revista de comunicación, (8), 105-135. https://raco.cat/index.php/ObraDigital/ article/view/301178

Lovato, A. (2014). Documental Multimedia Interactivo. Una excusa para reinventar el periodismo digital. En Irigaray, F. y Lovato, A. (Eds.). Hacia una comunicación transmedia. Editorial de la Universidad Nacional de Rosario.

Miles, A. (2014). Materialism and interactive documentary: sketch notes. Studies in Documentary Film, 8(3), 205-220. https://doi.org/10 $.1080 / 17503280.2014 .958894$

Nash, K. (2012). Modes of interactivity: analysing the webdoc. Media, Culture \& Society, 34 (2), 195-210. https://doi. org/10.1177/0163443711430758

Nash, K. (2014). Strategies of interaction, questions of meaning: an audience study of the NFBs Bear 71. Studies in Documentary Film, 8(3) 221-234. https://doi.org/10.1080/17503280.2014.958904

Porto Renó, D. (2013). Diversidade de modelos narrativos para documentários transmídia. Doc On line, (14), 93-112. http://doc.ubi.pt/14/ dossier_denis_reno.pdf

Ramos, M. M. (2020). Nuevas voces en el documental latinoamericano a través del cine ensayo como herramienta para el cambio

\section{ocm Observatorio deCibermedios}

\section{https://observatoriocibermedios.upf.edu/}

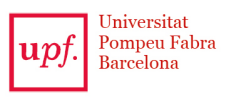

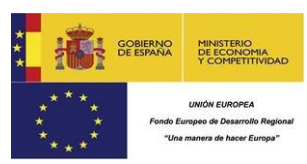

El Observatorio de Cibermedios es una producción del Grupo de Investigación en Documentación Digital y Comunicación Interactiva (DigiDoc) del Departamento de Comunicación de la Universitat Pompeu Fabra.

El Observatorio de Cibermedios (OCM) forma parte del proyecto del Plan Nacional "Narración interactiva y visibilidad digital en el documental interactivo y el periodismo estructurado". RTI2018-095714-B-C21 (MINECO/FEDER), Ministerio de Ciencia, Innovación y Universidades (España). 
social. Área Abierta, 20(3), 301-315. https://doi.org/10.5209/ arab.69584

Rodríguez, M. I. y Molpeceres, S. (2013). Los nuevos documentales multimedia interactivos: construcción discursiva de la realidad orientada al receptor activo. Historia y Comunicación Social, (18), 249-262. https://doi.org/10.5209/rev_HICS.2013.v18.44325

Scolari, C. (2014). Narrativas transmedia: nuevas formas de comunicar en la era digital. Anuario AC/E de cultura digital, 1, 71-81.

Toffler, A. (1980). La tercera ola. Plaza \& Janés Editores.

Torres-Martín, J. L. (2019). El proyecto 'La memoria de los peces': la comunicación transmedia como herramienta para la recuperación de la memoria histórica. En Sedeño-Valdellós, A. (Coord.). Arte, activismo y comunicación en el ámbito académico, (pp. 123-139). Dykinson.

Vázquez-Herrero, J. y López-García, X. (2018). Actores implicados en la consolidación del documental interactivo. Hipertext.net, (17), 32-42. https://doi.org/10.31009/hipertext.net.2018.i17.04

Vázquez-Herrero, J., Negreira-Rey, M. C. y Pereira-Fariña, X. (2017). Contribuciones del documental interactivo a la renovación de las narrativas periodísticas: realidades y desafíos. Revista Latina de Comunicación Social, (72), 397-414. https://doi.org/10.4185/RLCS2017-1171

Wimmer, R. D. y Dominick, J. R. (1996). La investigación científica de los medios de comunicación: una introducción a sus métodos. Bosch.

\section{CV}

José Luis Torres-Martín. Doctor en Comunicación Audiovisual por la Universidad de Málaga. Docente e investigador en el Departamento de Comunicación Audiovisual y Publicidad de la Facultad de Ciencias de la Comunicación de la Universidad de Málaga desde 2011. Actualmente es miembro del grupo de investigación PAIDI Investigación sobre Transformaciones en el Ecosistema de la Comunicación (Transcomunicar) y del proyecto de investigación Las aplicaciones (apps) para la realización de textos audiovisuales en directo: características funcionales y análisis de interfaces. Sus líneas de investigación versan sobre narrativas transmedia, redes sociales y estudios de género en la ficción audiovisual. Desarrolló su actividad profesional como redactor, operador de cámara y realizador en diferentes medios de comunicación andaluces durante 16 años.

Andrea Castro-Martínez. Doctora en RR. PP. y Publicidad por la Universidad de Málaga, Sevilla, Cádiz y Huelva con Mención Internacional. Docente e investigadora en la Universidad de Málaga desde 2016. Fue durante ocho años subdirectora de los grados de Comunicación y Diseño en EADE, sede de la Universidad de Gales en Málaga, donde también era docente de los grados y del MBA. Licenciada en Comunicación Audiovisual y en Publicidad y RR.PP. por la UMA, ha cursado varios posgrados y un MBA. Ha trabajado en diferentes medios y ha sido docente y consultora de comunicación. Autora de más de una treintena de publicaciones, sus líneas de investigación son relaciones públicas, comunicación estratégica, comunicación interna, nuevas formas publicitarias y comunicación con perspectiva de género. Actualmente es miembro de varios grupos y proyectos de investigación.

Pablo Diaz-Morilla. Doctor en Publicidad y RR. PP. por la Universidad de Málaga, Sevilla, Cádiz y Huelva con Mención Internacional. Director y docente en los Grados en Comunicación en EADE University of Wales in Málaga desde 2007 y de las Enseñanzas Artísticas Superiores en Diseño en la institución docente malagueña León XIII desde 2014. Licenciado en Comunicación Audiovisual por la UMA y Experto en Marketing 3.0 por la UNIR. Ha sido docente e investigador en el departamento de Comunicación Audiovisual y Publicidad de la Universidad de Málaga. Autor de más de una veintena de publicaciones, sus líneas de investigación se centran en la aplicación de las nuevas formas publicitarias a la comunicación comercial, la comunicación organizacional y la comunicación interna.

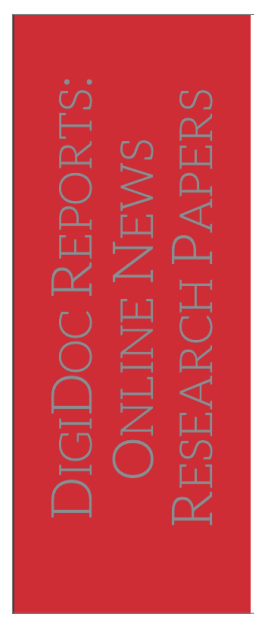

\section{Researching the news in the hybrid media system: An expert panel report} Irene Costera Meijer, Richard Rogers, Oscar Westlund \& Tamara Witschge 